\title{
Prevalence of HIV Infection and Resistance Mutations in Patients Hospitalized for Febrile Illness in Indonesia
}

\author{
Tuti P. Merati, ${ }^{1}$ Muhammad Karyana, ${ }^{2,3}$ Emiliana Tjitra, ${ }^{2}$ Herman Kosasih, ${ }^{3^{\star}}$ Abu T. Aman, ${ }^{4}$ Bachti Alisjahbana, ${ }^{5}$ Dewi Lokida, ${ }^{6}$ \\ Dona Arlinda, ${ }^{2,3}$ Frank Maldarelli, ${ }^{7}$ Aaron Neal, ${ }^{8}$ Mansyur Arif, ${ }^{9}$ Muhammad Hussein Gasem, ${ }^{10}$ Nurhayati Lukman, ${ }^{3}$ \\ Pratiwi Sudarmono, ${ }^{11}$ Chuen-Yen Lau, ${ }^{7}$ Usman Hadi, ${ }^{12}$ Vivi Lisdawati, ${ }^{13}$ Wahyu Nawang Wulan, ${ }^{3} \mathrm{H}$. Clifford Lane, ${ }^{8}$ and \\ Sophia Siddiqui ${ }^{8}$ \\ ${ }^{1}$ Faculty of Medicine, Universitas Udayana, Denpasar, Indonesia; ${ }^{2}$ National Institute of Health Research and Development, Ministry of Health, \\ Republic of Indonesia, Jakarta, Indonesia; ${ }^{3}$ Indonesia Research Partnership on Infectious Disease (INA-RESPOND), Jakarta, Indonesia; ${ }^{4}$ Faculty \\ of Medicine, Universitas Gadjah Mada, Yogyakarta, Indonesia; ${ }^{5}$ Faculty of Medicine, Universitas Padjadjaran, Bandung, Indonesia; ${ }^{6}$ Department \\ of Clinical Pathology, Tangerang District Hospital, Tangerang, Indonesia; ${ }^{7}$ National Cancer Institute, National Institutes of Health, Bethesda, \\ Maryland; ${ }^{8}$ National Institute of Allergy and Infectious Diseases, National Institutes of Health, Bethesda, Maryland; ${ }^{9}$ Faculty of Medicine, \\ Universitas Hasanudin, Makassar, Indonesia; ${ }^{10}$ Faculty of Medicine, Universitas Diponegoro, Semarang, Indonesia; ${ }^{11}$ Faculty of Medicine, \\ Universitas Indonesia, Jakarta, Indonesia; ${ }^{12}$ Faculty of Medicine, Universitas Airlangga, Surabaya, Indonesia; ${ }^{13}$ Sulianti Saroso, Infectious \\ Disease Hospital, Jakarta, Indonesia
}

\begin{abstract}
HIV prevalence in Indonesia is increasing, and only $64 \%$ of infected individuals know their status. In a prospective cohort of 1,453 hospitalized patients with unexplained fever, $46(3.2 \%)$ had HIV, including 15 (1.1\%) patients without a prior HIV diagnosis. Among 31 subjects previously known to have HIV, $21(68 \%)$ had been receiving combination antiretroviral therapy (cART) at the time of enrollment. Of 39 HIV cases with HIV RNA levels $\geq 100 \mathrm{copies} / \mathrm{mL}$, sequencing for genotype analysis and resistance testing was successful in 30 (77\%) subjects. The most common HIV subtypes were AE (90\%) and B (10\%). Five (16.7\%) subjects had resistance mutations to nucleoside and nonnucleoside reverse transcriptase inhibitors, and all of them were on cART. No evidence of transmitted drug resistance was found in newly diagnosed individuals. Hospital-based screening may be an efficient method to expand HIV testing and identify a significant number of new cases. Access to care, close monitoring, expansion of anti-retroviral options, and ensuring availability of CD4 determinations, viral load testing, and genotyping are crucial to control of the epidemic in Indonesia.
\end{abstract}

\section{BACKGROUND}

Indonesia has an estimated HIV prevalence of approximately $0.3 \%$ ( $\sim 800,000$ individuals). ${ }^{1}$ The majority of people living with HIV (PLWH) are 25-49 years; youth $<19$ years old account for $5.8 \% .^{2}$ Though the epidemic is concentrated in several centers, with approximately $19 \%$ of reported HIV infections in the capital Jakarta, cases are dispersed throughout urban and rural areas across 2,342 islands spanning over $5,000 \mathrm{~km}^{2}$ In 2020, $64 \%$ of PLWH knew their status; only $34 \%$ of those positive were on antiretroviral therapy (ARV), of whom $17 \%$ were virally suppressed. ${ }^{3}$ Thus, Indonesia is far from the UNAIDS 95-95-95 targets, ${ }^{4}$ in which 95\% of PLWH know their HIV status, 95\% of people who know their status are on ARV, and $95 \%$ of those on ARV have suppressed viral loads. Testing is conducted at prenatal clinics, tuberculosis clinics, and through targeted campaigns in high-risk populations; new testing initiatives are essential and are being developed. One consideration for identifying PLWH is screening of acutely febrile hospitalized patients because clinical manifestations of acute HIV infection and HIV-associated co-infection can include fever. Here we describe the potential opportunity for implementing HIV testing in this setting. In addition, we evaluate genotypes and resistance mutations to facilitate epidemiologic characterization of HIV in Indonesia.

*Address correspondence to Herman Kosasih, Indonesia Research Partnership on Infections Disease, Jalan Percetakan Negara No. 29, Jakarta, Indonesia 10560. E-mail: hkosasih@inarespond.net

\section{MATERIALS AND METHODS}

Study design and participants. This study was conducted as a sub-analysis of a larger observational study designed to identify etiologies of acute febrile illness in hospitalized patients (AFIRE). The AFIRE study ${ }^{5}$ enrolled 1,486 individuals aged $\geq 1$ year with fever $\left(>38^{\circ} \mathrm{C}\right)$ for $<15$ days admitted for evaluation at eight large referral hospitals in seven provincial Indonesian capitals between July 2013 and June 2016. To avoid enrollment of subjects with chronic infection as the cause of fever, patients were excluded from the study if they had subjective fever for more than 2 weeks or were hospitalized in the preceding 3 months. Specimens were collected at baseline, at convalescence (14-28 days), and at 3 months post admission. For the second and third specimens, patients were invited to return to the hospital if already discharged. Clinical data and hospital laboratory results were documented, and additional diagnostic tests (molecular and serological assays) were completed at INARESPOND laboratories. ${ }^{6}$ For this analysis, 33 participants were excluded due to insufficient specimens.

HIV testing. HIV testing was performed retrospectively in 2017 on samples obtained at 3 months (convalescent specimens) using two antibody-based rapid diagnostic tests (RDTs) for qualitative detection of antibodies to HIV type 1 (gp-120, gp-41, p24), type 2 (gp-36), and subtype $O$ (Oncoprobe ${ }^{\circledR}$ Utama [Jakarta, Indonesia] and SD diagnostics). If negative, no further testing was performed. If positive, all available samples were tested using a fourthgeneration ELISA (Bio-Rad, Hercules, CA) and reverse transcription-polymerase chain reaction (RT-PCR) as described below to address the possibility of acute infection 
or infection occurring between hospitalization and collection of the 3-month specimen. For 441 subjects without a 3-month sample, a fourth generation ELISA and RT-PCR were performed in addition to the two RDTs mentioned above at baseline and at 14-28 days to detect acute or chronic infection.

HIV-1 RNA screening was performed via 1) a one-step quantitative RT-PCR assay detecting a conserved region (nucleotide 510-588) of the gag $\mathrm{ORF}^{7}$ and 2) a conventional PCR assay targeting an 812-bp region of the gag gene. ${ }^{8}$ Specimens positive for HIV-1 RNA were sequenced for ARV resistance and subtype profiles based on a 1,273-bp nucleotide sequence $(2,527-3,800$ of HIV-1 HXB2 genome numbering) of the RT gene. ${ }^{8}$ HIV subtype was determined from the sequence using REGA subtyping algorithm. ${ }^{9}$

Statistical analysis and ethical clearance. Descriptive statistics were calculated using Stata 13 (StataCorp, LLC, College Station, TX). This study was approved by the Institutional Review Board of the National Institutes of Health Research and Development, Ministry of Health, Indonesia. All participants provided informed consent prior to enrollment.

\section{RESULTS}

Among 1,486 enrolled individuals, 1,453 subjects had available specimens. Forty-six subjects (41 adult, 5 pediatric) were HIV positive, indicating an overall prevalence of $3.2 \%$, with $4.8 \%(41 / 855)$ and $0.8 \%(5 / 598)$ attributable to adult and pediatric patients, respectively (Table 1). Review of clinical records revealed that 31/46 individuals had previously diagnosed HIV infection at enrollment. Among participants with no known history of HIV, 15/1,422 (1.1\%) had undiagnosed HIV infections. Nine of these subjects were diagnosed by their clinical teams during hospitalization, and six subjects were diagnosed after discharge based on testing at the INA-REPOND laboratory (Table 1). In five of the six retrospective diagnoses, all tests were positive, indicating chronic untreated infections. In one subject, the two RDTs were negative, but the fourth-generation ELISA and RT-PCR were positive, suggesting acute HIV infection.

Among the 15 patients with newly diagnosed HIV, common presenting characteristics included 13 (87\%) with a lymphocyte count $\leq 20 \%$, 8 (53\%) with anemia, 6 (40\%) with cough and dyspnea, 5 (33\%) with diarrhea, 5 (33\%) with weight loss, 2 (13\%) with decreased consciousness, and $2(13 \%)$ with peeling skin and pruritis. Their clinical diagnoses at the time of admission included 5 (33\%) with community-acquired pneumonia, 4 (27\%) with tuberculosis, 2 (13\%) with dengue, 2 (13\%) with gastroenteritis, 1 (7\%) with typhoid fever, and 1 (7\%) with tonsillitis.

Based on available data, 21/31 (68\%) subjects previously known to have HIV had been receiving combination antiretroviral therapy (cART) at the time of enrollment, and seven $(33 \%)$ of these were documented to have HIV RNA levels $<100$ copies $/ \mathrm{mL}$.

Of 39 HIV cases with HIV RNA levels $\geq 100$ copies $/ \mathrm{mL}$, sequencing for genotype analysis and resistance testing was successful in 30 (77\%) subjects. The majority (27) were subtype $A E$, and 3 were subtype $B$, including the subject with acute HIV infection. Five (17\%) subjects had resistance mutations. All five were documented as receiving cART. No evidence of transmitted drug resistance was found in the 15 newly diagnosed individuals. Each resistance sequence possessed a distinct pattern, including multiple thymidine

TABLE 1

Patient characteristics, HIV treatment regimens, and laboratory findings for 46 subjects hospitalized with fever and diagnosed as having HIV ( 41 adults, 5 pediatric $[<19$ years old])

\begin{tabular}{|c|c|c|c|c|}
\hline & $\begin{array}{l}\text { HIV negative } \\
(N=1,407)\end{array}$ & $\begin{array}{l}\text { Previously known } \\
\qquad(N=31)\end{array}$ & $\begin{array}{c}\text { Diagnosed during } \\
\text { hospitalization }(N=9)\end{array}$ & $\begin{array}{l}\text { Diagnosed retrospectively } \\
\qquad(N=6)\end{array}$ \\
\hline \multicolumn{5}{|l|}{ Demography } \\
\hline Age (years), median (range) & $21(1-98)$ & $30(5-46)$ & $34.5(26-55)$ & $30(6-35)$ \\
\hline Pediatric/adult & $593 / 814$ & $4 / 27$ & $0 / 9$ & $1 / 5$ \\
\hline Sex (male) & 777 & 23 & 7 & 5 \\
\hline ARV treatment, $n$ & N/A & 21 & 6 & $\mathrm{~N} / \mathrm{A}$ \\
\hline AZT/3TC/nevirapine & & 9 & 1 & \\
\hline TDF/3TC/efavirenz & & 8 & 5 & \\
\hline D4T /3TC/nevirapine & & 1 & 0 & \\
\hline TDF/3TC/LPV/r & & 1 & 0 & \\
\hline AZT/3TC/efavirenz & & 1 & 0 & \\
\hline TDF/FTC/nevirapine & & 1 & 0 & \\
\hline Undocumented ARV treatment & & 10 & 3 & \\
\hline Laboratory HIV viral detection, $n$ & $\mathrm{~N} / \mathrm{A}$ & 31 & 9 & 6 \\
\hline Virus detected $(\geq 100$ copies $/ \mathrm{mL})$ & & 24 & 9 & 6 \\
\hline Undetected (<100 copies/mL) & & 7 & 0 & 0 \\
\hline Resistance & N/A & 5 & 0 & 0 \\
\hline Genotype performed, $n$ & $\mathrm{~N} / \mathrm{A}$ & 18 & 7 & 5 \\
\hline Subtype A (01_AE) & & 17 & 6 & 4 \\
\hline Subtype B & & 1 & 1 & 1 \\
\hline \multicolumn{5}{|l|}{ Complete blood count, median (range) } \\
\hline $\mathrm{Hgb}(\mathrm{g} / \mathrm{dL})$ & $13.1(3.3-20.8)$ & $9.7(5.9-16.2)$ & $10.2(8.9-13.4)$ & $13(7.6-16.2)$ \\
\hline WBC count (cells $/ \mu \mathrm{L})$ & $6,800(500-70,500)$ & $6,500(700-14,900)$ & $7,200(3,600-14,800)$ & $9,050(6,300-17,100)$ \\
\hline Lymphocyte count (\%) & $20(0-97.9)$ & $14(3.6-40.4)$ & $10.9(5.3-20.7)$ & $11.1(6.2-74)$ \\
\hline Lymphocyte count (absolute) & $1,189(0-20,152)$ & $770(97-4,038)$ & $784(439-1,264)$ & $1,108(731-7,104)$ \\
\hline Mortality, $n(\%)$ & $70(5)$ & $12(38.7)$ & $3(33.3)$ & $2(33.3)$ \\
\hline During hospitalization & $41(2.9)$ & $8(25.8)$ & $2(22.2)$ & 2 (33.3) \\
\hline 3 months post hospitalization & $29(2.1)$ & $4(12.9)$ & $1(11.1)$ & $0(0)$ \\
\hline
\end{tabular}

ARV = antiretroviral; N/A = not available; $\mathrm{WBC}=$ white blood cell. 
analog mutations, mutations conferring resistance to other nucleoside reverse transcriptase inhibitors and mutations indicating resistance to non-nucleoside reverse transcriptase inhibitors (Table 2). Two of these subjects died-one during hospitalization and one 3 months after hospitalization.

Fifteen adults and two pediatric subjects with HIV died, including the subject with probable acute HIV infection. Overall mortality was $37 \%$ (17/46) among PLWH subjects, compared with $5 \%(70 / 1,406)$ among the non-HIV group $(P<0.01) 3$ months after hospitalization. Mortality rates for patients with previously diagnosed HIV and patients with unknown prior HIV status were similar (32.4\% versus 33\%). Four subjects died with tropical coinfections (two Rickettsia typhi and two Salmonella spp.), and another five subjects died due to co-infections with $M$. tuberculosis (3), sepsis due to $P$. aeruginosa (1), and $S$. pneumonia (1). An etiology other than HIV was not identified in eight subjects. Four of the 29 surviving subjects had co-infection with dengue virus (3) or measles virus (1).

For the four pediatric subjects known to be HIV positive, median age was 7 years (range: $5-8$ years). Two were male. Two pediatric subjects had documented ARV regimens (1 D4T/3TC/Nevirapine and 1 TDF/3TC/LPV/r); both had detectable 01_AE subtype. The first subject had measles virus co-infection, and the second subject had Bordetella pertussis and Streptococcus pneumonia co-infections; both subjects survived. The two cases with Mycobacterium tuberculosis co-infections were fatal, although the HIV was sensitive to all ARV drugs. The subject diagnosed retrospectively by this study was a 6-year-old boy with cough, sore throat, and skin rash and had a clinical diagnosis of tonsilitis.

\section{DISCUSSION}

HIV infection is a substantial public health challenge for Indonesia, which remains one of the few countries with an increasing number of new infections yearly. ${ }^{10}$ Indonesia has an overall HIV prevalence of approximately $0.3 \%$ and annual incidence of 46,659 (2018), 50,282 (2019), and 41,397 (2020). ${ }^{2,11}$ The HIV epidemic in Indonesia, as elsewhere, is concentrated in key populations, including injection drug users, men who have sex with men, transgender women (or "waria"), and commercial sex workers. Many of these are groups that are challenging to reach by traditional testing approaches, such as voluntary counseling and testing. New initiatives to achieve the 95-95-95 goals of UNAIDS are in process, and additional opportunities to engage key populations are needed. Fever as a cause of hospitalization is common in Indonesia, though testing for HIV is not a routine part of care. Screening patients with fever for HIV infection may be an effective tool for identification of PLWH because clinical manifestations of acute HIV infection and HIV associated co-infections can include fever.

In this cohort, $3.2 \%$ of subjects admitted to the hospital for evaluation of unexplained fever were HIV positive, and one-third of these were not previously known to be HIV positive. Positivity rates among those admitted for fever and with unknown HIV status was 3.5-fold higher than overall estimates of HIV prevalence, suggesting that routine HIV testing of hospitalized patients could yield a significant number of new diagnoses. Considering the limited ability of the government to provide free testing, this approach could focus on individuals with certain clinical syndromes (e.g., tuberculosis, pneumonia, chronic diarrhea) and laboratory parameters (e.g., lymphopenia, anemia), with an emphasis on those from key populations.

Prior research supports the effectiveness of targeted screening. A cost-effectiveness study of routine testing to determine the HIV prevalence for 14 different indicator conditions in 20 European countries showed that 10 indicator conditions (hepatitis B and C, infectious mononucleosis-like syndrome, unexplained lymphadenopathy, pneumonia, peripheral neuropathy, seborrheic dermatitis, cervical dysplasia, and malignant lymphoma) had HIV prevalence of $>0.1 \% .^{12}$ Studies among patients with fever admitted to health care facilities demonstrated that routine HIV testing may identify acute HIV infection in patients with suspected endemic illnesses, such as malaria in Kenya ${ }^{13}$ and Uganda, ${ }^{14}$ acute mononucleosis in the United States, ${ }^{15}$ dengue in Singapore, ${ }^{16}$ and currently COVID-19 globally. ${ }^{17}$ Other studies among patients admitted to medical, surgical, and emergency departments found that $0.13 \%$ were positive for HIV, among whom $78 \%$ had chronic HIV infection. Such infections may be missed without routine HIV testing in the

TABLE 2

Major antiretroviral resistance mutations identified in five subjects to nucleoside reverse transcriptase Inhibitors (NRTIs) and non-nucleoside reverse transcriptase Inhibitors (NNRTIs). Genotypic SUSCEPTIBILITY SCORES (GSSs) for the current treatment regimen are shown. Also shown are the GSS scores if the regimen was changed to include a protease inhibitor (PI) or an integrase strand transfer inhibitor (INSTI)

\begin{tabular}{|c|c|c|c|c|c|c|c|c|}
\hline Study participant, city & Age (years) & Current ART regimen & Outcome & Subtype & $\begin{array}{l}\text { Drug-resistant } \\
\text { mutations, NRTI }\end{array}$ & $\begin{array}{l}\text { Drug-resistant } \\
\text { mutations, NNRTI }\end{array}$ & Overall GSS ${ }^{\star}$ & $\begin{array}{l}\text { Optimal GSS with PI } \\
\text { and INSTI option }\end{array}$ \\
\hline \#1, Denpasar & 36 & $\mathrm{AZT}+3 \mathrm{TC}+\mathrm{EFV}$ & Survived & $\mathrm{AE}$ & $\begin{array}{c}\text { D67N, K70E, } \\
\text { M184V, K219R }\end{array}$ & $\begin{array}{c}\text { K103N, P225H, } \\
\text { K238T, N348I }\end{array}$ & 1 & 3 \\
\hline \#2, Yogyakarta & 8 & $\mathrm{TDF}+3 \mathrm{TC}+\mathrm{LPV} / \mathrm{r}$ & Survived & $\mathrm{AE}$ & $\begin{array}{c}\text { D67N, K70E, } \\
\text { M184V, K219R }\end{array}$ & $\begin{array}{c}\text { K101E, V108I, } \\
\text { G190A }\end{array}$ & 1 & 2 \\
\hline \#3, Yogyakarta & 25 & $A Z T+3 T C+N V P$ & Survived & AE & M184V & $\begin{array}{c}\text { Y181C, G190A, } \\
\text { P225H }\end{array}$ & 1 & 3 \\
\hline \#4, Yogyakarta & 30 & TDF+FTC+NVP & Died & B & T215Y, K219N & K101E, Y181C & 2 & 3.5 \\
\hline \#5, Yogyakarta & 33 & TDF+3TC+EFV & Died & AE & M184V & $\begin{array}{c}\text { A98G, K103N, } \\
\text { Y318F }\end{array}$ & 1 & 2 \\
\hline
\end{tabular}

\footnotetext{
ARV = antiretroviral.
}

* "For each drug prescribed, a GSS value of 1 was assigned if resistance interpretation identified no resistance or potential low-level resistance. A GSS of 0.5 was assigned to prescribed drugs with intermediate resistance or low-level resistance, and a value of 0 was assigned to drugs with high-level resistance. The arithmetic sum of the individual scores for the specific drugs prescribed provided the total GSS of that treatment. Patients were grouped corresponding to the number of active drugs prescribed: $<2 ; 2-2.5$; and $\geq 3$. Thus, a value of $\geq 3$ indicates a fully active regimen, and values of $<3$ indicate increasingly higher drug resistance and secondarily increasingly less residual antiviral potency of the antiretroviral regimen" (quoted verbatim from Gonzalez-Serna, Journal of Antimicrobial Chemotherapy, 2017). ${ }^{31}$ 
hospital setting. ${ }^{18-20}$ Our study has shown that screening during hospitalization for acute febrile illness may identify both acute and chronic HIV infections.

Given our high observed mortality of $33 \%$ in PLWH with previously unknown HIV status, HIV screening of hospitalized patients is a good opportunity for diagnosis, linkage to care, and appropriate treatment, including access to cART. The high proportion of PLWH presenting to hospitals with advanced disease, as suggested by presenting illness severity, highlights the potential value of routine screening, particularly in high-risk populations. Furthermore, the high mortality rate in those with known HIV suggests gaps in clinical care, consistent with the low proportion of patients with documented CD4 and/or viral load data as well as the number of patients with viral loads $\geq 100$ copies $/ \mathrm{ml}$ despite being on therapy. It is important to note that not all healthcare facilities in Indonesia have the capacity to perform CD4 and viral load testing. Although our findings should not be generalized beyond the large referral hospital setting, we have identified a likely opportunity for improving HIV detection and management in Indonesia.

As reflected in our cohort, the number of pediatric $(<14$ years old) patients hospitalized for acute fever in Indonesia is relatively low (3.5\%). One subject receiving second-line ARV (1 TDF/3TC/LPV/r) showed resistance to first-line HIV treatment, per the Indonesian guidelines. The two fatal co-infections with $M$. tuberculosis had HIV sensitive to first line ARV, but adherence was low. Challenges to optimal adherence include the limited number of pediatric ARV formulations, side effects, daily medication requirements, and the need for ongoing support from extended family for those whose parents have died. The case of missed HIV diagnosis during hospitalization highlights the importance of careful history taking, physical examination, and laboratory evaluation. ${ }^{11,21}$ Because mother-to-child transmission is the most common etiology of pediatric HIV in Indonesia, a program providing HIV prevention, diagnosis, and treatment to young girls, women living with HIV, and pregnant women unaware of their status was started in 2012.

Drug resistance was not detected in cART-naive individuals in this study. Prior studies found relatively low rates of transmitted drug resistance in Indonesia. ${ }^{22,23}$ Our prevalence of drug resistance in treatment-experienced individuals $(5 / 30,16.7 \%)$ was within the range of previous reports $\left(6 \%\right.$ in Papua ${ }^{24}$ and $23.7 \%$ in North Sulawesi ${ }^{25}$ ). Lack of clinician awareness of drug resistance in four of five subjects suggests a need for expanded access to resistance testing in addition to closer monitoring of clinical manifestations, CD4 count, and viral load to optimize management strategies.

Viral resistance profiles in our cohort reflect the antiretroviral drugs used as first-line therapy in Indonesia, specifically zidovudine (AZT), lamivudine (3TC), and efavirenz. It is unlikely that patients with the resistance profiles identified in our study would be suppressed using options currently available in Indonesia. The complexity of the observed resistance profiles to reverse transcriptase inhibitors indicates that the use of protease inhibitors and integrase strand transfer inhibitors will be important ARV choices for patients who have already been treated with ARV, especially those with lower Genotypic Susceptibility Scores (Table 2). It would be of great value to modify the currently available formulary to include these agents so that treatment options can be expanded, particularly where first-line regimens have been in use for an extended period of time. More effective and easier-to-use regimens would increase compliance and minimize development and transmission of drug resistance. $^{26}$ Recent approval of dolutegravir in Indonesia, though only for treatment-experienced patients with resistance to at least two ARVs, is a step in the right direction. ${ }^{27}$

Our study suggests several strategies that could improve HIV detection and management in Indonesia: 1) implement routine HIV testing for all patients presenting for hospitalization with fever, 2) educate health care providers on HIV detection and management strategies, 3) expand the ART formulary in Indonesia, and 4) 4ducate patients about HIV, including the importance of adherence to treatment.

Routine HIV testing for all individuals with fever entering the health care system should be considered. The frequency of such screening might be more for those at high risk, those presenting with certain clinical syndromes, or those with certain laboratory abnormalities. This approach has been implemented in other countries, including Bostwana, Uganda, Haiti and South Africa, with a resultant increase in both inpatient and outpatient testing. ${ }^{28}$ Implementation of hospitalbased testing in three Vancouver hospitals for patients admitted to the emergency department and to medical and surgical units resulted in a positive testing rate of $0.13 \%$, with more acute infections diagnosed in hospitalized patients. ${ }^{18}$ Training health care professionals to recognize the clinical presentation of acute HIV infection will also enable earlier initiation of cART and appropriate counseling to reduce the risk of transmission. Identification of early HIV infection requires a high index of suspicion and knowledge of laboratory methods ${ }^{29}$ and will be particularly important in Indonesia where current HIV incidence is low $(\sim 48,300$ cases; 18.2 per 100,000 population) per year ${ }^{1}$ but is increasing rapidly. ${ }^{30}$ The currently available formulary should also be modified to include antiretrovirals that will expand treatment options, particularly where available regimens are exhausted, to increase compliance and limit transmitted drug resistance. ${ }^{26}$ Counseling of patients regarding their disease status, importance of adherence, connection to care, detected resistance, and any necessary modification of cART should also be standard in HIV management. Because quantitative RT-PCR and sequencing for ARV resistance were performed retrospectively in our study, results were reported back to the patients' primary doctors, who provided adherence counseling and switched to second-line therapy.

The data presented in this manuscript were collected as part of a larger parent study on acute febrile illness requiring hospitalization; the parent study was not designed to assess HIV. Thus, this sub-study was limited in its ability to broadly target patients at risk for HIV. For example, exclusion of patients with a history of hospitalization in the past 3 months may have caused us to miss undiagnosed advanced HIV cases because these patients often have recurrent hospitalizations associated with opportunistic infections.

Access to treatment, close monitoring, ensuring that CD4 determinations, viral load testing, and genotyping are increasingly available will be crucial to curbing the epidemic in Indonesia. A more aggressive program will preserve treatment options and decrease the burden of severe illness on 
the health care system. Early implementation of these advances will reap substantial benefit.

Received December 17, 2020. Accepted for publication July 1, 2021.

Published online August 30, 2021.

Acknowledgments: We thank the following study sites and teams for their participation: Dr. Cipto Mangunkusumo Hospital (Jakarta), Prof. Dr. Sulianti Saroso Infectious Disease Hospital (Jakarta), Dr. Hasan Sadikin Hospital (Bandung), Dr. Kariadi Hospital (Semarang), Dr. Sardjito Hospital (Yogyakarta), Dr. Soetomo Hospital (Surabaya), Sanglah Hospital (Denpasar), and Dr. Wahidin Soedirohusodo Hospital (Makassar).

Financial support: This work was supported by the Ministry of Health of the Republic of Indonesia, the National Institute of Health Research and Development, Badan Litbangkes, Indonesia. This project has been funded in whole or in part with Federal funds from the National Institute of Allergy and Infectious Diseases, National Institutes of Health, under contract Nos. HHSN261200800001E and HHSN261201500003I. The funders had no role in study design, data collection and analysis, decision to publish, or preparation of the manuscript.

Authors' addresses: Tuti P. Merati, Faculty of Medicine, Universitas Udayana, Denpasar, Indonesia, E-mail: tutiparwati@yahoo.com. Muhammad Karyana and Dona Arlinda, National Institute of Health Research and Development, Ministry of Health, Republic of Indonesia, Jakarta, Indonesia, and Indonesia Research Partnership on Infectious Disease (INA-RESPOND), Jakarta, Indonesia, E-mails: mkaryana@gmail.com and arlindona1@gmail.com. Emiliana Tjitra, National Institute of Health Research and Development, Ministry of Health, Republic of Indonesia, Jakarta, Indonesia, E-mail: etjitra@ yahoo.com. Herman Kosasih, Nurhayati Lukman, and Wahyu Nawang Wulan, Indonesia Research Partnership on Infectious Disease (INA-RESPOND), Jakarta, Indonesia, E-mails: hkosasih@ ina-respond.net, unurhayati@ina-respond.net, and wwahyunawang@ gmail.com. Abu T. Aman, Faculty of Medicine, Universitas Gadjah Mada, Yogyakarta, Indonesia, E-mail: atholib04@yahoo.com. Bachti Alisjahbana, Faculty of Medicine, Universitas Padjadjaran, Bandung, Indonesia, E-mail: b.alisjahbana@gmail.com. Dewi Lokida, Department of Clinical Pathology, Tangerang District Hospital, Tangerang, Indonesia, and Indonesia Research Partnership on Infectious Disease (INA-RESPOND), Jakarta, Indonesia, E-mail: lokidadewi@yahoo.com. Frank Maldarelli and Chuen-Yen Lau, National Cancer Institute, National Institutes of Health, Bethesda, MD, E-mails: fmalli@mail.nih.gov and chuen-yen.lau@nih.gov. Aaron Neal, H. Clifford Lane, and Sophia Siddiqui, National Institute of Allergy and Infectious Disease, National Institutes of Health, Bethesda, MD, E-mails: aaron.neal@nih.gov, clane@niaid.nih.gov, and ssiddiqui@niaid.nih.gov. Mansyur Arif, Faculty of Medicine, Universitas Hasanudin, Makassar, Indonesia, E-mail: mansyurarif64@gmail.com. Muhammad Hussein Gasem, Faculty of Medicine, Universitas Diponegoro, Semarang, Indonesia, E-mail: mhgasem@gmail.com. Pratiwi Sudarmono, Faculty of Medicine, Universitas Indonesia, Jakarta, Indonesia, E-mail: psdrmn@yahoo. com. Usman Hadi, Faculty of Medicine, Universitas Airlangga, Surabaya, Indonesia, E-mail: usmanhadi@sby.centrin.net.id. Vivi Lisdawati, Sulianti Saroso, Infectious Disease Hospital, Jakarta, Indonesia, E-mail: viandrashakti@gmail.com.

\section{REFERENCES}

1. Directorate Generale of Disease Prevention and Control, 2018. Progress Report HIV-AIDS and STD in Indonesia 2017. Jakarta, Indonesia: Ministry of Health.

2. Kementerian Kesehatan Indonesia, 2020. Profil Kesehatan Indonesia Tahun 2019. Jakarta, Indonesia: Kementerian Kesehatan Indonesia.

3. Indonesia Diperkirakan Gagal Capai Target Global, 2020. Akhiri HIVIAIDS Pada 2030. Available at: https://www.suaramer deka.com/news/nasional/249006-indonesia-diperkirakan- gagal-capai-target-global-2020-akhiri-hivaids-pada-2030. Accessed February 26, 2021.

4. UNAIDS, 2021. 2025 AIDS Targets. Available at: https://www. unaids.org/sites/default/files/2025-AIDS-Targets_en.pdf. Accessed May 17, 2021.

5. Gasem MH et al., 2020. An observational prospective cohort study of the epidemiology of hospitalized patients with acute febrile illness in Indonesia. PLoS Negl Trop Dis 14: e0007927.

6. Karyana $\mathrm{M}$ et al., 2015. INA-RESPOND: a multi-centre clinical research network in Indonesia. Health Res Policy Syst 13: 34.

7. Palmer $S$ et al., 2003. New real-time reverse transcriptaseinitiated PCR assay with single-copy sensitivity for human immunodeficiency virus type 1 RNA in plasma. $J$ Clin Microbiol 41: 4531-4536.

8. Yabar CA, Acuna M, Gazzo C, Salinas G, Cárdenas F, Valverde A, Romero S, 2012. New subtypes and genetic recombination in HIV type 1-infecting patients with highly active antiretroviral therapy in Peru (2008-2010). AIDS Res Hum Retroviruses 28: 1712-1722.

9. Stanford University, 2014. HIV Drug Resistance Database. Available at: http://dbpartners.stanford.edu:8080/RegaSubtyping/ stanford-hiv/typingtool/. Accessed May 8, 2020.

10. Januraga PP et al., 2018. The cascade of HIV care among key populations in Indonesia: a prospective cohort study. Lancet HIV 5: 11.

11. Nurjannah N, 2020. Kebijakan Test dan Treat Untuk HIV AIDS. Disease Prevention and Control, Indonesian Ministry of Health. Presented at 2020 Halodoc seminar. Jakarta, Indonesia, January 28, 2021, via Zoom.

12. Raben D et al., 2019. Improving the evidence for indicator condition guided HIV testing in Europe: results from the HIDES II Study - 2012-2015. PLoS One 14: e0220108.

13. Sanders EJ, Mugo P, Prins HA, Wahome E, Thiong'o AN, Mwashigadi $G$, van der Elst EM, Omar A, Smith AD, Graham SM, 2014. Acute HIV-1 infection is as common as malaria in young febrile adults seeking care in coastal Kenya. AIDS 28: 1357-1363.

14. Bebell LM et al., 2010. Acute HIV-1 infection is highly prevalent in Ugandan adults with suspected malaria. AIDS 24: 1945-1952.

15. Pincus JM, Crosby SS, Losina E, King ER, LaBelle C, Freedberg KA, 2003. Acute human immunodeficiency virus infection in patients presenting to an urban urgent care center. Clin Infect Dis 37: 1699-1704.

16. Verrall AJ, Lye DC, Pada S, Smitasin N, Lee CK, Khoo MJ, Koay ES, Leo YS, Fisher DA, Archuleta S, 2018. High yield of HIV testing in dengue-like febrile illness in Singapore. Open Forum Infect Dis 5: ofy 171 .

17. Ciccullo A, Borghetti A, Dusina A, Segala FV, Visconti E, Tamburrini E, Cauda R, Di Giambenedetto S, 2021. The need to continue testing for HIV, even during the coronavirus disease 2019 (COVID-19) pandemic. HIV Med 22: e3-e4.

18. Gustafson R et al., 2020. Routine HIV testing in acute care hospitals: changing practice to curb a local HIV epidemic in Vancouver, BC. Prev Med 137: 106132.

19. Rucker MG, Eavou R, Allgood KL, Sinclair D, Lawal R, Tobin A, Pitrak D, Glick NR, 2016. Implementing routine HIV screening in three Chicago hospitals: lessons learned. Public Health Rep 131(Supp/ 1): 121-129.

20. Nanditha NGA, St-Jean M, Tafessu H, Guillemi SA, Hull MW, Lu M, Henry B, Barrios R, Montaner JSG, Lima VD, 2019. Missed opportunities for earlier diagnosis of HIV in British Columbia, Canada: a retrospective cohort study. PLoS One 14: e0214012.

21. Yuniar $Y$, Handayani $R, 2019$. Challenges and social support provisions in the treatment of HIV infected children in Indonesia. Health Science Journal of Indonesia 10: 103-110.

22. Kotaki $T$, Khairunisa $S Q$, Witaningrum AM, Sukartiningrum MMQY, Diansyah SD, Rahayu MN, Nasronudin RP, Kameoka M, 2015. HIV-1 transmitted drug resistance mutations among antiretroviral therapy-naive individuals in Surabaya, Indonesia. AIDS Res Ther 12: 5.

23. Witaningrum AM, Kotaki $T$, Khairunisa SQ, Yunifiar MMQ, Indriati DW, Bramanthi R, Nasronudin, Kameoka M, 2016. 
Genotypic characterization of human immunodeficiency virus type 1 derived from antiretroviral therapy-naive individuals residing in Sorong, West Papua. AIDS Res Hum Retroviruses 32: 812-817.

24. Hutapea HML, Fitriana E, Natalia El, Wahyuni T, Adiningsih S, Widiyanti M, 2018. The description of antiretroviral resistance mutation in people living with HIV-AIDS (PLWHA) in districts/ city in Papua Province. Buletin Penelitian Kesehatan 46: 199-206.

25. Ueda S, Witaningrum AM, Khairunisa SQ, Kotaki T, Nasronudin, Kameoka M, 2019. Genetic diversity and drug resistance of HIV-1 circulating in North Sulawesi, Indonesia. AIDS Res Hum Retroviruses 35: 407-413.

26. lacob SA, lacob DG, Jugulete G, 2017. Improving the adherence to antiretroviral therapy, a difficult but essential task for a successful HIV treatment-clinical points of view and practical considerations. Front Pharmacol 8: 831.

27. Assyifa A, 2020. Dolutegravir, Angin Segar untuk Pengobatan HIV. Available at: https://kumparan.com/bandungkiwari/
dolutegravir-angin-segar-untuk-pengobatan-hiv-1smoROL 5S09/full. Accessed May 8, 2020.

28. Bassett IV, Walensky RP, 2010. Integrating HIV screening into routine health care in resource-limited settings. Clin Infect Dis 50 (Supp/ 3): S77-S84.

29. Maniar AJ, Maniar JK, Kamath R, Shah S, Verma R, Kinloch S, 2008. Primary HIV-1 infection-a "window of opportunity" for healthcare providers. J Assoc Physicians India 56: 628-632.

30. Cairns G, 2020. Indonesia: Tackling HIV in One of the World's Fastest-Growing Epidemics. Available at: http://www. aidsmap.com/Indonesia-tackling-HIV-in-one-of-the-worldsfastest-growing-epidemics/page/3331208/. Accessed May 8, 2020.

31. Gonzalez-Serna A, Glas AC, Brumme CJ, Poon AFY, De La Rosa AN, Mudrikova T, Lima VD, Wensing AMJ, Harrigan R, 2017. Genotypic susceptibility score (GSS) and CD4+ T cell recovery in HIV-1 patients with suppressed viral load. J Antimicrobial Chem 72: 496-503. 